\title{
CARCINOMA OF THE OESOPHAGUS AS A COMPLICATION OF ACHALASIA OF THE CARDIA
}

BY

\author{
J. L. WILLIAMS \\ From Llandough Hospital, Penarth, Glam.
}

(RECEIVED FOR PLBLICATION MARCH 9, 1956)

Carcinoma of the oesophagus is an unusual complication of achalasia of the cardia. Since Fagge described the first case in 1872, only 26 further proven cases have been described in the literature.

Baer and Sicher reviewed the literature in 1947 and found eight cases, and added one of their own. They excluded those reported by Guisez, Cade, Letulle, and Albu on the grounds of insufficient evidence. A further search of the literature has brought to light other cases, and all that I have been able to find up to the present day are summarized in Table I. Gottstein (1908) mentioned three further examples but gave no details, so they are not included here.

A further case is now reported, bringing the total to 28 .

\section{CASE History}

R.W.S., a man aged 41 years, who was a machinist. 을 was admitted to hospital on April 20, 1955, with a history of loss of weight, anorexia, pyrexia, and a productive cough over the previous three months. This was at first diagnosed as influenza. Five weeks before admission his voice became hoarse, and during the previous three weeks he could only talk in a whisper. He occasionally vomited large amounts of undigested food, streaked with blood.

Since childhood he had had difficulty in swallowing some solid foods, which appeared to stick behind the lower end of the sternum. He had had frequent attacks of vomiting. but these diminished with increasing age, and his dysphagia had not increased lately. $\mathrm{He}$ had always coughed up whitish sputum in the morning, but this had become purulent in the last three months.

TABLE I

A SUMMARY OF CASES REPORTED IN THE LITERATURE

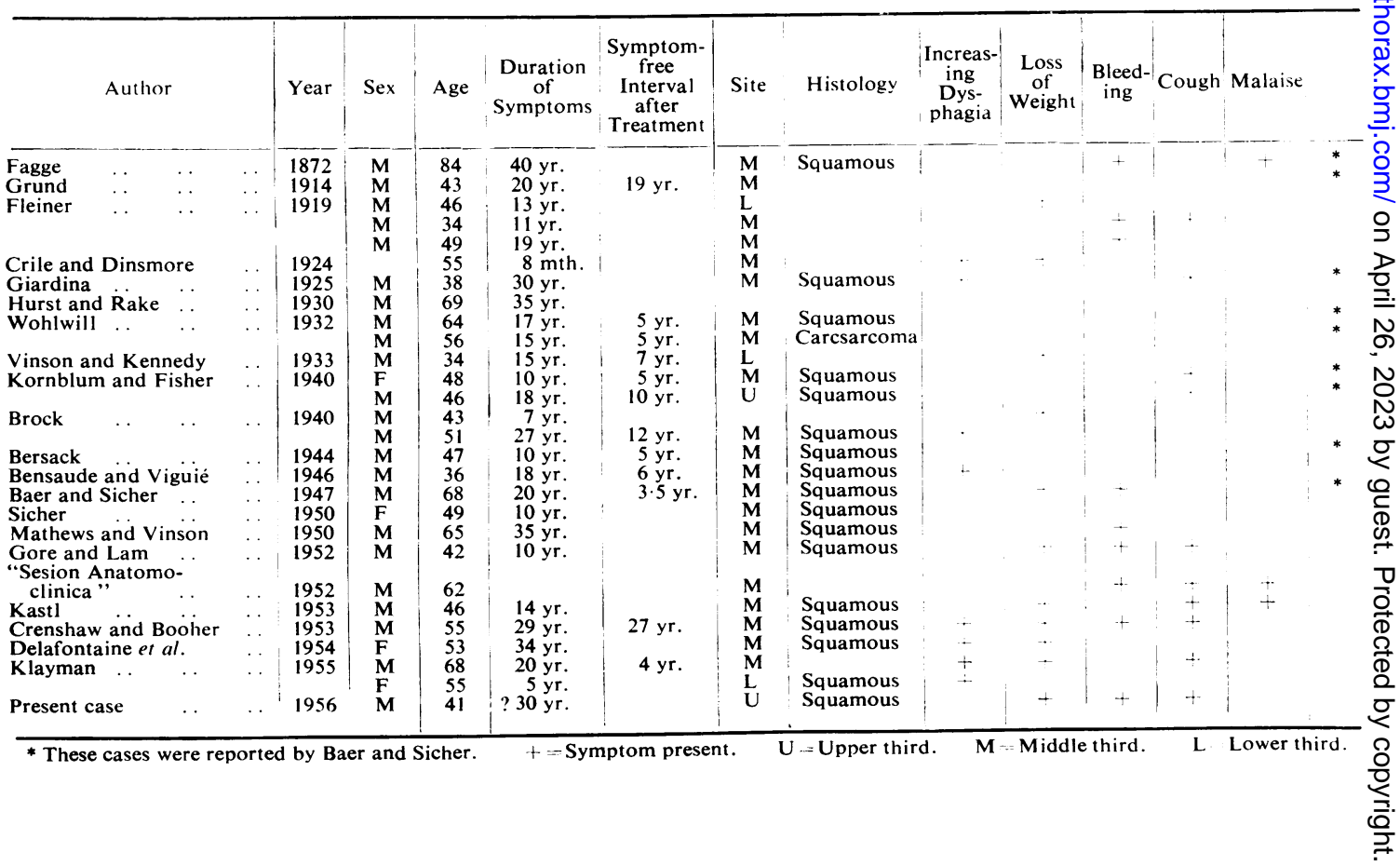




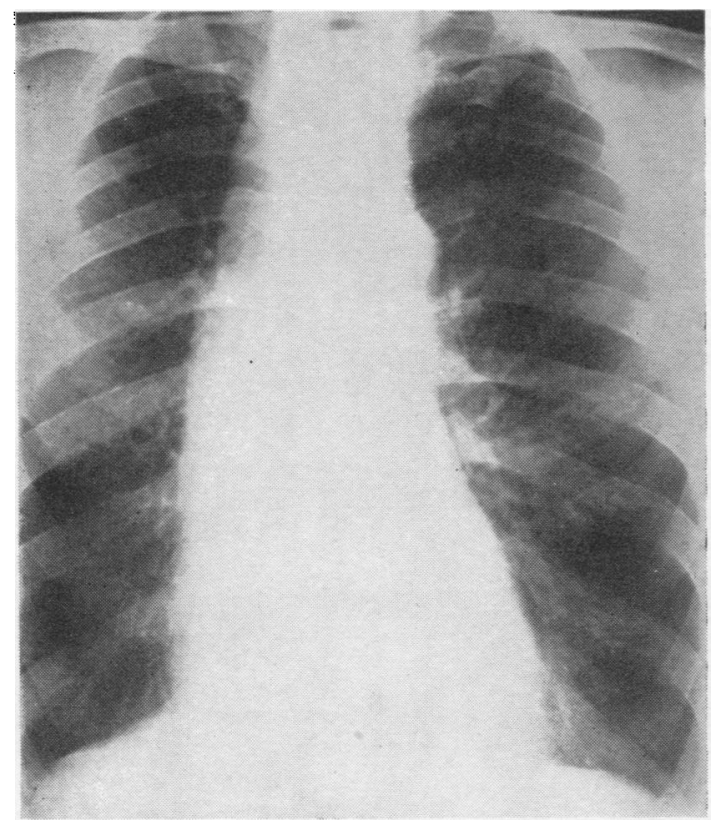

FIG. 1.-Radiograph taken in 1953 showing the widened mediastinal shadow.

While in the R.A.F. in 1940 a chest radiograph is said to have revealed some abnormality. An abnormal mediastinal shadow had been observed on mass miniature radiography in 1953 (Fig. 1). He had had no treatment.

On examination he was an ill, pale man who had lost a lot of weight. He spoke in a whisper, the fingers were clubbed, and moist sounds were heard over both lung fields. There were no other abnormal physical signs. On the night of admission he vomited a large amount of bright red blood, which necessitated a blood transfusion.

A chest radiograph showed marked enlargement of the mediastinal shadow to the right (Fig. 2), and compared with the previous films which had been taken in 1953, widening of the upper third of the mediastinal shadow.

A barium-meal examination at the chest clinic, just before admission, showed a dilated oesophagus with a filling defect, which we interpreted at first as being due to food residue.

Indirect laryngoscopy (Mr. Hector Thomas) showed both vocal cords to be immobile, and fixed in an abnormally abducted position. He thought that the filling defects in the chest clinic radiographs could be due to an extensive carcinoma of the oesophagus, and on subsequent oesophagoscopy found a friable bleeding growth, situated just below the level of the cricoid. The oesophagoscope could not be passed beyond the growth, although a bougie passed behind it easily. A biopsy of the growth showed a squamous-celled carcinoma.

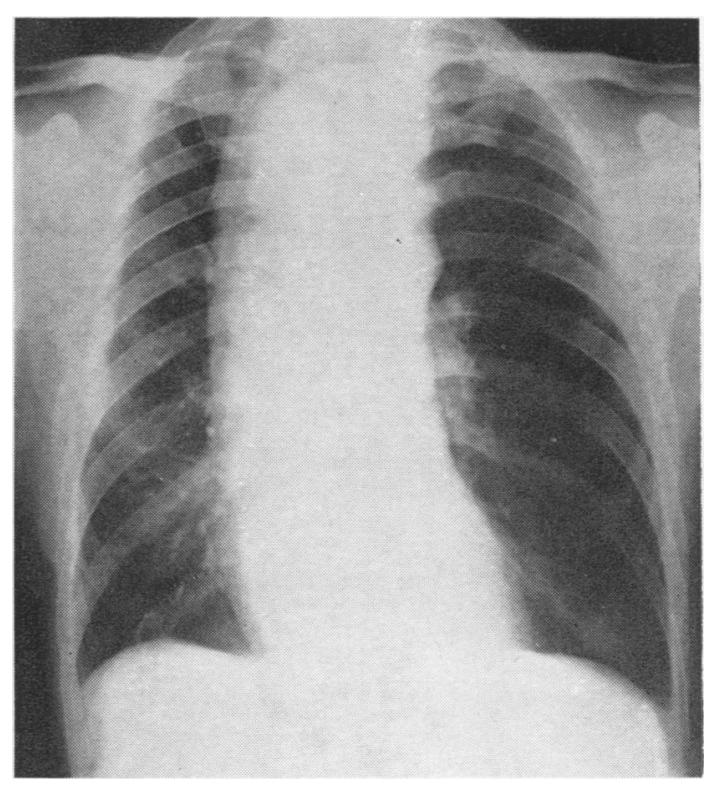

Fig. 2.-Radiograph taken on admission showing widening of the upper third of the mediastinal shadow as compared with Fig. 1.

A repeat barium swallow (Dr. Hinde) confirmed the presence of a greatly dilated oesophagus, containing a fluid level in its lower third (Fig. 3) and a smooth conical lower end (Fig. 4). The barium passed slowly into the stomach and its rate of flow was not appreciably altered by the inhalation of octyl nitrite. A very large irregular filling defect was demonstrated in the upper third of the oesophagus (Figs. 3-5). The right diaphragm on screening was seen to be partially paralysed.

The growth was considered to be inoperable. The patient's condition rapidly deteriorated due to bronchopneumonia, and he died following a further haemorrhage on May 2, 1955.

NECROPSY.-Dr. J. K. Storring performed the necropsy.

Below the diaphragm the oesophagus showed a constriction with no evidence of any organic lesion. Proximally, the oesophagus was dilated in its entire extent, its widest part measuring $19 \mathrm{~cm}$. in circumference. Its wall was thickened and the mucosa showed a whitish discoloration and was desquamated in places (Figs. 6 and 7). The upper third was occupied by a large tumour measuring 11 by 9 by $7 \mathrm{~cm}$. which was fixed to the anterior wall of the oesophagus and had ulcerated through into the left main bronchus $1.5 \mathrm{~cm}$. below the bifurcation of the trachea.

The lungs showed areas of bronchopneumonia which were confluent and extensive in the left upper lobe. The paratracheal and mediastinal lymph nodes were enlarged and completely surrounded the left recurrent laryngeal nerve. The right recurrent laryngeal 


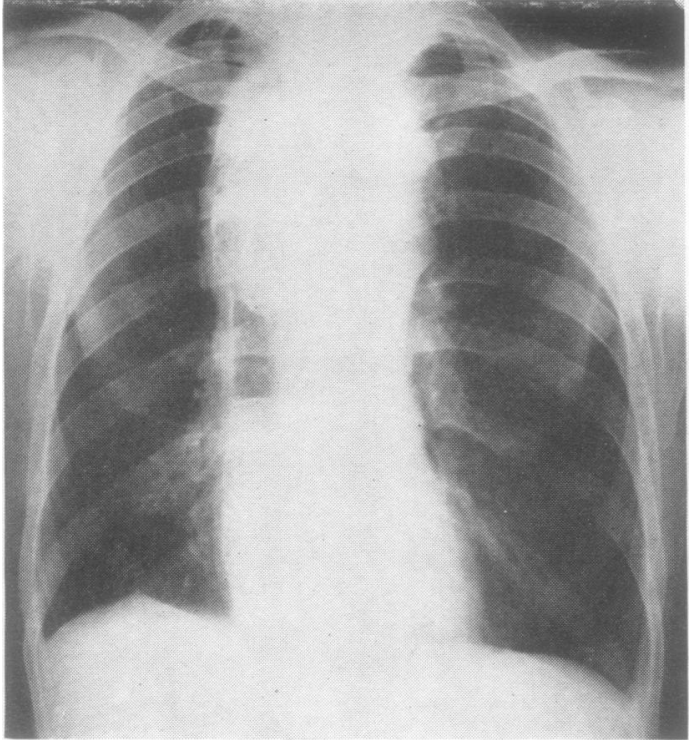

Fig. 3

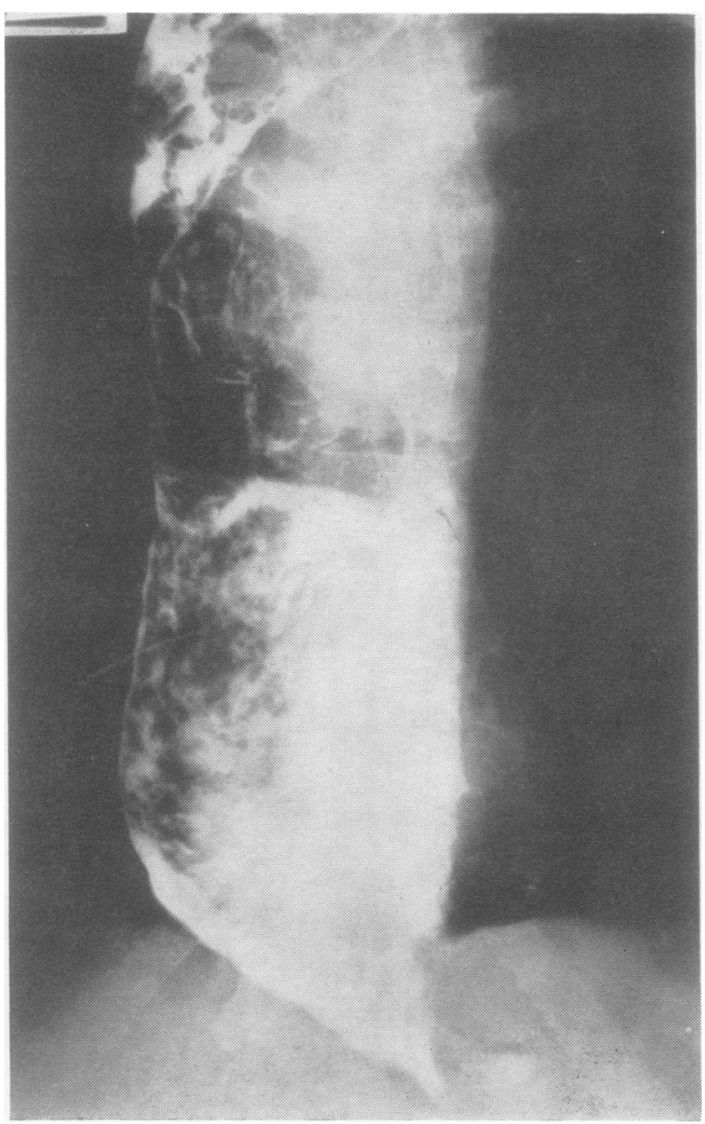

Fio. 4

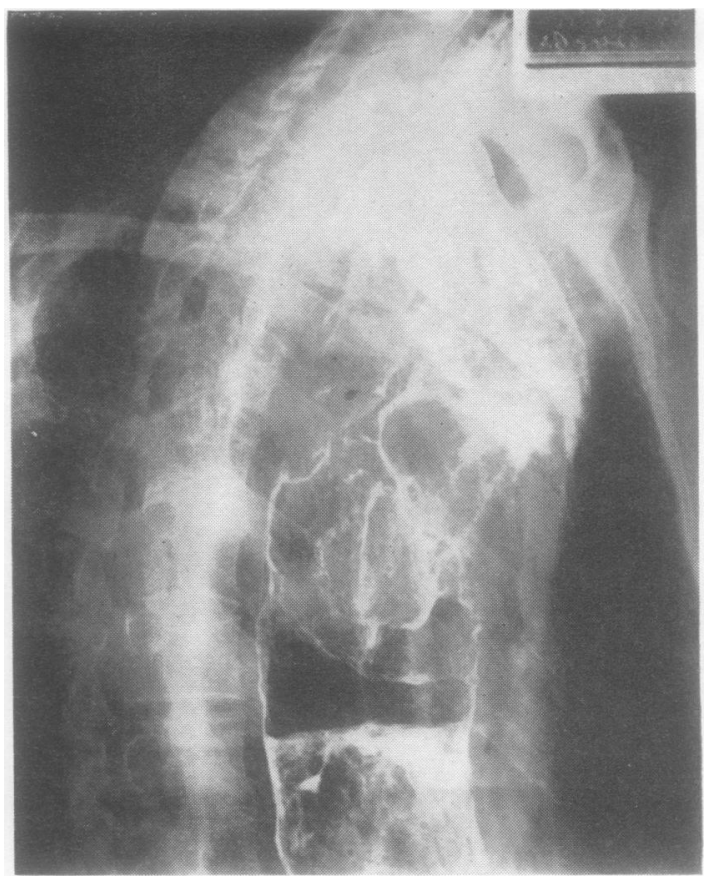

FIG. 5

FIG. 3.-Barium swallow showing a very dilated oesophagus with a fluid level and a mass in its upper third.

Fig. 4.-Barium swallow showing a dilated oesophagus, cardia region, and filling defect.

N

FIG. 5.-Barium swallow showing the filling defect in the upper third. $\mathrm{N}$

은

Fig. 6.-The dilated oesophagus and upper end of the stomach seen $\omega$ from the right side.

FiG. 7.-The oesophagus opened to show the large growth in the $\frac{\mathrm{C}}{\mathbb{1}}$ upper,third. 
nerve was completely free of growth, as was the left phrenic nerve. The right phrenic nerve was displaced laterally by the oesophageal growth. The larynx and trachea were normal and there were no other metastases demonstrated.

HistoloGY.-The oesophageal growth was a well - differentiated keratinizing squamous - celled carcinoma, which had infiltrated through to the mucosa of the left main bronchus. Only one of the eight mediastinal lymph nodes examined showed tumour metastasis, the others reactive hyperplasia only. Sections from the wall of the middle third of the oesophagus showed fibrous tissue overgrowth in all layers and muscle hypertrophy.

There was no evidence of leucoplakia. The epithelium was thickened and in places had become desquamated, leaving only a thin layer of cells. The lamina propria and submucosa were infiltrated with lymphocytes and plasma cells. The appearances were those of a chronic oesophagitis with muscle hypertrophy. The lungs showed areas of bronchopneumonia.

\section{INCIDENCE}

Although Fleiner (1919) reported three examples of carcinoma of the oesophagus which had occurred in 40 patients with achalasia of the cardia, Gottstein (1908) three in 33, and Rake (1931) three in 15, Mathews and Vinson (1950) found only three in 1,000 patients.

In the Registrar-General's report for 1931 this association was not present in 208 cases of death from cancer of the oesophagus (RegistrarGeneral's 1947 Decennial Supplement, England and Wales, 1931). The sex incidence in this series is males:females $6: 1$, which compares with $5: 1$ by Vinson (1940) for cancer of the oesophagus. Cardiospasm is said to occur more frequently in women than in men (Aird, 1949).

If achalasia of the cardia were a predisposing cause to cancer of the oesophagus, one would have expected a higher incidence of this association, and a higher incidence in women.

The average time in which symptoms of achalasia of the cardia had been present in the series reviewed in this paper was 17.7 years, and, in 12 cases in which data are available, an average of seven years had elapsed between the last treatment and the appearance of the carcinoma.

On comparing the age incidence of carcinoma in the present series with that obtained from the Registrar-General's figures for teaching and nonteaching hospitals, there is a significant difference ; carcinoma occurs at a much lower age in patients with achalasia of the cardia (RegistrarGeneral's 1954 Statistical Review of England and Wales for 1949). The mean age of the cases of cancer of the oesophagus at teaching hospitals was

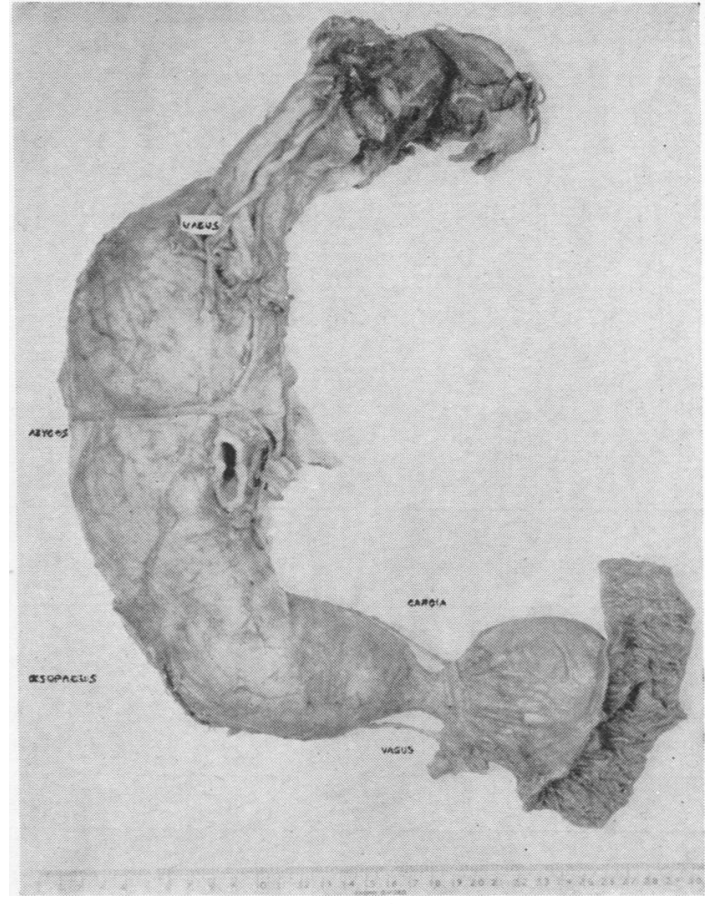

Fig. 6

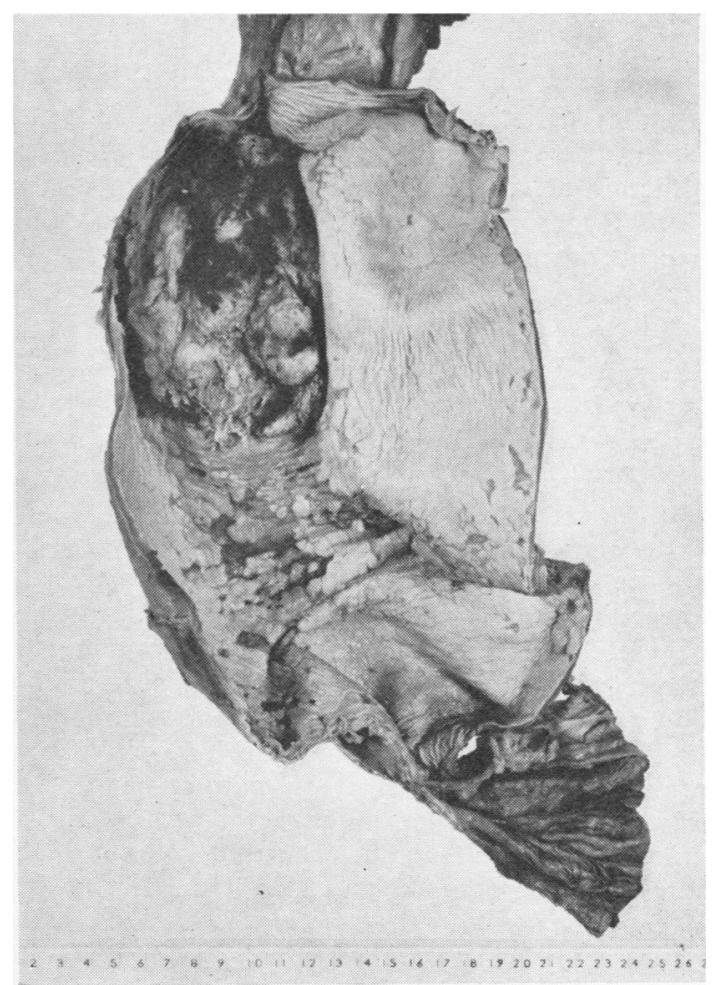

FIG. 7 
$63.5 \pm 0.63$ years and for non-teaching hospitals $67.1 \pm 1.5$; the difference $=3.6 \pm 1.62$ years, and is therefore just significant. The mean age of this series was $51.6 \pm 2.71$ for males and $51.2 \pm 1.43$ for females, difference $=0.36 \pm 3.06$, and is not significant. For males and females combined, it is $51.6 \pm 2.32$.

Combining the males and females in one series and comparing them with the teaching hospitals,

TABLE II

COMPARISON OF NUMBER OF CASES OF CANCER OF THE OESOPHAGUS IN EACH AGE GROUP IN THIS SERIES WITH THOSE REPORTED BY THE REGISTRAR-GENERAL IN HOSPITAL PATIENTS

\begin{tabular}{c|c|c}
\hline Age Group & $\begin{array}{c}\text { No. Reported in } \\
\text { Teaching and Non- } \\
\text { teaching Hospitals }\end{array}$ & $\begin{array}{c}\text { No. Reported in } \\
\text { Present Series (M. } \\
\text { and F. Combined) }\end{array}$ \\
\hline $15-24$ & $2(0 \cdot 5 \%)$ & $2(7.4 \%)$ \\
$25-34$ & 8 & $2 \cdot 0 \%)$ \\
$35-44$ & $16(4 \cdot 0 \%)$ & $6(22 \cdot 2 \%)$ \\
$45-54$ & $51(12 \cdot 8 \%)$ & $9(33 \cdot 3 \%)$ \\
$55-64$ & $106(26 \cdot 5 \%)$ & $5(18 \cdot 5 \%)$ \\
$65-75$ & $156(39 \cdot 0 \%)$ & $4(14 \cdot 8 \%)$ \\
$76+$ & $61(15 \cdot 2 \%)$ & $1(3 \cdot 7 \%)$ \\
\hline
\end{tabular}

we have a difference of $11.9 \pm 2.4$ years, which is significant, and with the non-teaching hospitals $15.5 \pm 2.8$, also a significant difference.

On comparing the number of cases occurring in each age group (Table II) it is seen that in the hospital patients only $19 \%$ are under 55 years, and in this series $63 \%$ are below this level. Thus, although achalasia of the cardia does not appear to predispose to cancer of the oesophagus, should it occur it appears at a much younger age.

\section{Pathology}

The majority of the reported cases showed a very extensive carcinoma, often of the cauliflower type, with invasion into the surrounding structures. Histologically, they were squamous-celled carcinomata.

In $80.7 \%$ the carcinoma was found in the middle third of the oesophagus, with $11.6 \%$ in the lower third and $7.7 \%$ in the upper third. In three of these multiple papillomata were present; in two a smaller carcinoma was also present further down the oesophagus (there were no papillomata or leucoplakia), and in one case leucoplakia was present. This incidence of carcinoma in the middle third is much higher than that usually quoted for carcinomata occurring de novo, the corresponding figures being 35,50 , and $15 \%$ (Aird, 1949).

Rake (1931) postulated that an oesophagitis resulted from stasis of the oesophageal contents and the resulting bacterial growth. Shallow ulcers $\overrightarrow{0}$ resulted and papillomata appeared, following 음 attempts at regeneration of the mucosa. These $\frac{\bar{c}}{\frac{}{2}}$ papillomata later became malignant. If this were $\stackrel{\mathbb{\Omega}}{\varrho}$ true one should have expected a higher incidence of malignant change in the lower third of the oesophagus where stasis is most marked.

Fleiner (1919) suggested that malignant change $\overrightarrow{\vec{\omega}}$ took place following trauma by repeated $\stackrel{\sim}{\sim}$ bouginage. Here again, it is reasonable to sup- $\vec{x}$ pose that the upper and lower ends of the oesophagus would be subjected to greater trauma than $\vec{A}$ the greatly dilated middle third, and thus should is have had a higher incidence of malignant change. $\infty$

In six cases a fistula was present: one into the 은 trachea ; two into the right main bronchus; one into both main bronchi; and one into the left $D$ main bronchus. In one case the site was not $\stackrel{\mathbb{\varnothing}}{\mathbb{8}}$ stated.

\section{Diagnosis}

Diagnosis often presented difficulty, as the $\vec{\varphi}$ patients had already had vomiting and difficulty in oु swallowing, and further symptoms were readily attributed to the same cause.

Dysphagia.-This was the commonest symptom of carcinoma occurring in an otherwise normal oesophagus. Owing to the great size of the oesophagus in achalasia of the cardia, this symptom was very late in appearing or was not present at all. As seen in Table III increasing dysphagia was present in under half the cases.

TABLE III

INCIDENCE OF SYMPTOMS

\begin{tabular}{|c|c|c|}
\hline $\begin{array}{l}\text { Symptoms } \\
\text { (21 Cases) }\end{array}$ & $\begin{array}{l}\text { Percentage } \\
\text { of Cases }\end{array}$ & $\begin{array}{l}\text { Percentage of Cases as } \\
\text { Presenting Symptoms }\end{array}$ \\
\hline 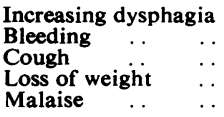 & $\begin{array}{l}42 \cdot 8 \\
38 \\
47 \cdot 6 \\
47 \cdot 6 \\
9 \cdot 5\end{array}$ & $\begin{array}{l}36 \cdot 8 \\
26 \cdot 3 \\
21 \cdot 1 \\
15 \cdot 7 \\
-\end{array}$ \\
\hline
\end{tabular}

Cough.-Cough sometimes occurred following $\stackrel{\sim}{N}$ the aspiration of oesophageal contents into the trachea. In the case presented here a productive $\stackrel{\mathcal{N}}{\mathrm{N}}$ cough with pyrexia was the first indication that a $\mathrm{\omega}$ malignant change had occurred. In the series of collected cases a productive cough was present in half the number, but this was explained in over half of them by the presence of a fistula between ? the oesophagus and the bronchial tree (six out of the 10 cases).

BLEEDING.-Fleiner (1919) attributed bleeding to trauma after bouginage, but in most cases it $\varnothing$ was a symptom of the carcinoma itself. Only in 
three had it occurred previously, and in these there was no oesophagoscopic evidence as to whether it was due to trauma or to a pre-existing papilloma.

The site of the bleeding was the carcinoma itself, which presented a large and friable surface (Fig. 7). Together with pulmonary infection this was the commonest cause of death, as is shown in the case presented here.

Loss of WEIGHT.-This was an unusual symptom of achalasia of the cardia, but occurred in almost half of these malignant cases.

Other Symptoms.-The case presented here had bilateral recurrent nerve palsy with resulting loss of voice. The paralysis on the left side was explained by the involvement of the nerve in the growth. The right recurrent nerve was free of the growth and the paralysis it caused is difficult to explain; the vocal cords were curiously abducted on both sides.

RADIOGRAPHS.-Radiographs of the chest showed a widened mediastinal shadow but did not usually suggest the presence of a carcinoma. In our case the mediastinal shadow had widened compared with previous radiographs and this was proved to be due to the growth itself. In the majority of these cases barium swallow examination showed the greatly dilated oesophagus and narrowed cardia, but in four of the cases it failed to show the carcinoma at the first screening. In two of these cases, following other evidence, a repeated barium swallow revealed the carcinoma. The main difficulty was the presence of food residues in the oesophagus, and Kornblum and Fisher (1940) emphasize the importance of washing out the oesophagus very thoroughly before this examination.

In our patient screening examination also showed a partial paralysis of the right diaphragm ; this was explained at necropsy by the stretching of the right phrenic nerve over the growth.

Oesophagoscopy.-Adequate washing out of the oesophagus is essential before oesophagoscopy because in four of these cases oesophagoscopy failed to show a lesion. In the case reported by Delafontaine, Viguie, Rensonnet, Pradel, and Vergoz (1954) a carcinomatous ulcer was not seen on two oesophagoscopies, despite its having already been demonstrated on barium meal examination and the diagnosis of carcinoma of the oesophagus with achalasia of the cardia having been made. This diagnosis was then set aside, and a Heller operation performed. The dysphagia disappeared but pyrexia continued and the patient returned in three months with a large carcinoma of the oesophagus.

In a case reported by Klayman (1955) no carcinoma was seen on barium swallow examination or on oesophagoscopy ; however, exfoliated carcinoma cells were found in the oesophageal aspirations and a second oesophagoscopy revealed an extensive carcinoma.

Cytology.-Klayman (1955) has reported the finding of exfoliated cancer cells in lavage of the oesophagus with Ringer's solution. He had 19 positive results in 20 cases of malignancy and no false positives in a further 20 benign lesions. Unsuspected carcinoma in achalasia of the cardia was correctly diagnosed in one case (see above), and in another case of achalasia of the cardia a correctly positive result was obtained when a previous oesophageal biopsy was negative.

\section{TreatmenT}

These patients presented late in the course of their illnesses and had large inoperable growths invading the surrounding structures. In only five was exploratory thoracotomy considered justifiable, and four of these were inoperable. The other patient died following resection.

In three further cases a Heller operation was performed. In one patient who had an inoperable growth an attempt was made to relieve the dysphagia. There was temporary relief in the swallowing of fluids. In one case no relief was obtained, and in the other dysphagia was relieved for three months but other signs persisted (see above).

In operable cases oesophagectomy with oesophago-gastrostomy or jejunostomy as applied to oesophageal carcinomata without achalasia might be the treatment of choice.

Radiotherapy is not indicated in most patients because of the extensive nature of the lesion and their poor general condition.

\section{SUMmaRY}

A case of carcinoma of the oesophagus which occurred in a patient who had achalasia of the cardia is described with a review of 27 further cases from the literature.

Loss of weight and bleeding were common presenting symptoms together with cough and increasing dysphagia. The latter symptom was present in under half the cases.

Thorough oesophageal lavage is essential before barium swallow or oesophagoscopic examinations. These should be repeated if negative, and if the 
symptoms persist, because in four patients a carcinoma had been overlooked on first examination.

Examination of oesophageal washings for carcinoma cells has been positive in two cases when oesophagoscopy and radiography failed to reveal the carcinoma.

Achalasia of the cardia does not appear to predispose to malignant change, but when the latter occurs it does so at a much earlier age.

Diagnosis was late owing to the late appearance of symptoms, especially dysphagia. The growth had reached a large size before it caused obstruction of the dilated oesophagus.

Treatment by resection was possible in only one out of five cases in which thoracotomy was considered justifiable.

I wish to thank Mr. D. B. E. Foster for permission to publish this case, Mr. Hector Thomas for the report on the laryngoscopy and oesophagoscopy, Dr. Hinde for the radiological investigations, Dr. J. K. Storring for the pathological reports, Dr. Graham for permission to use Fig. 1, Dr. Lewis-Faning for the statistical analysis and Table II, and Mr. L. Williams for the photographs.

\section{REFERENCES}

Aird, I. (1949). A Companion in Surgical Studies. Livingstone,

Edinburgh. Baer, P., and Sicher, K.(1947). Brit. J. Radiol., 20, 528.
Bensaude, A., and Viguié, R.(1946). Arch. Mal. Appar. dig., 35, 544.
Bersack, S. R. (1944). Radiology, 42, 220 .

Brock, R. C. (1940-41). Guy's Hosp. Rep., 90, 23.

Crenshaw, J. F., and Booher, R. J. (1953). Gastroenterology, 25, 385. W Crile G. W., and Dinsmore, R. (1924). Surg. Clin. N. Amer., 4, 863.

Delafontaine, P., Viguié, R., Rensonnet, P., Pradel, E., and Vergoz, D. (1954). Arch. Mal.' Appar. dig., 43, 97.
.

Fagge, C. H. (1872). Guy's Hosp. Rep., 3 ser., 17, 413.

Fleiner, W. (1919). Münch. med. Wschr., 66, 579 and 623.

Giardina, S. G. (1925). Arch. ital. Chir., 13, 72.

Gore, I., and Lam, C. R. (1952). J. thorac. Surg., 24, 43.

Gottstein, G. (1908). Allg. med. ZentZtg, 77, 563 .

Grund (1914). Münch. med. Wschr., 61, 1882.

Hurst, A. F., and Rake, G. W. (1930). Quart. J. Med., 23, 491.

Kastl, W. H. (1953). Surgery, 34, 123.

Klayman, M. I. (1955). Ann. intern. Med., 43, 33

Kornblum, K., and Fisher, L. C. (1940). Amer. J.Roentgenol. 43, 364 .

Mathews, E. C., and Vinson, P. P. (1950). Gastroenterology, 15, 747 .

Rake, G. (1931). Lancet, 2, 682.

Registrar-General (1954). Statistical Review of England and Wales

egistrar-General (1954). Statistical Review of England and
for 1949. Supplement on Hospital In-patient Statistics.

- (1947). Decennial Supplement, England and Wales, 1931. Part 4. Multiple or Secondary Causes of Death. H.M. Stationery Office, London.

"Sesion Anatomoclinica" (1952). Dia méd., 24, 1297.

Sicher, K. (1950). Brit. med. J., 1, 1117.

Vinson, P. P. (1940). The Diagnosis and Treatment of Diseases of the Esophagus. Thomas, Springfield, Illinois. Quoted by Bockus (1944).

- and Kennedy, F. S. (1933'. Amer. J. med. Sci., 186, 660.

Wohlwill, F. (1932). Med. Welt, 6, 800. 